Europe's Journal of Psychology, 7(2), pp. 359-373

www.ejop.org

\title{
Understanding and treatment of diffuse aches and pains of patients from tradition-bound cultures
}

Jan Ilhan Kizilhan

University of Freiburg

\begin{abstract}
Patients from collective cultures with a tradition-bound cultural background (e.g., people from the Middle East and some south European countries such as Italy and Greece), have a different perception of pain and different conceptions of healing, which up till now have not been sufficiently appreciated in modern multimodal therapeutic approaches. Inadequate knowledge of anatomy and bodily functions and traditional perceptions of pain (magic, curse, punishment, etc.) have a substantial influence on diagnostics. The pain experience is regarded holistically in relation to the body, rather than being confined to a particular part of the body. Limited access to psychological complains treatment often leads to diffuse pain. The ailing body expresses its state in social, collective, economic, migration historical, psychological and cultural terms. A multimodal interdisciplinary and culture-sensitive approach is required for the effective pain treatment of patients from a tradition-bound background.
\end{abstract}

Keywords: pain perception, disease perception, traditional medicine, collective culture, culture-sensitive psychotherapy

Introduction

The multifactorial disorder model (Gatchel, 2005; Kröner-Herwig, 2009) generally accepted by specialists today is based on the general assumption that biological, psychological and social factors are involved in somatoform pain symptoms. Indeed, the basis for the modern understanding of pain was laid in the 17th century; pain became a physically determined phenomenon. Around the middle of the 19th century, new methods were developed to deaden and anaesthetize pain. Since then, the interpretation and understanding of pain has been dominated by medical views. Sociocultural influences, which up to that time played an important role in 
dealing with pain, were pushed into the background (Schmiederbach, 2002; Gatchel et al. 2007). The debate in medical circles about the purpose and meaning of pain was intensified in the western world only in the beginning of the $20^{\text {th }}$ century. Unsatisfied with references to a purely bodily function, circumstantial reference was made by some to relevant expositions in philosophy, pedagogics and, somewhat later, in psychology (Gatchel \& Turk, 1999).

Cultural differences in the expression and experience of pain were first discussed in anthropological medical literature (Kleinman, 1980). In the Anglo-Saxon part of the world, it was not until the 1950s that the question as to whether the cultural background has a bearing on pain behaviour and pain perception and hence whether it is significant for treatment was addressed (Künzler, 2005). Some studies conducted in the USA showed that cultural differences in pain behaviour do exist (Zborowski, 1969; Turner, 1989). They revealed that both subjective pain intensity and pain sensation are closely associated with psychological factors such as attitude and motivation as well as with the ethnic background (Turner, 1989; Bates et al. 1993; McCracken et al. 2001).

German physicians and therapists report, for instance, that Turkish patients from rural areas and patients belonging to other ethnic groups from southern European countries present with diffuse whole-body pain more frequently than German patients (Sherman, 1943; Clark \& Clark, 1980; Glier \& Erim, 2007; Arratow, 1995).

Pain, like no other sensation, is characterised by cultural influences, which also have a corresponding influence on disease perception and the behaviour associated with it (Kirmayer, 2008). This article will discuss the perception of pain and possibilities of treating pain in migrants from family-oriented societies (which include southern Italy, Mediterranean countries and Asia, as opposed to people from what are regarded as individual-oriented societies, i.e., Europe, North America, Germany and the United Kingdom), who have migrated to Germany to live and work. The situation of refugees with PTSD in connection with pain will not be dealt with here because this would exceed the scope of the paper.

\section{Pain perception}

In archaic and antique civilisations of the Middle East (Babylonian, Assyrian and Egyptian medicine), pain perception was based on magic and religious ideas. The belief was that, e.g., headache and facial neuralgia were caused by anthropomorphic ghosts or that they were to be regarded as punishment for insulting the gods (Tainter, 1948). 
Babylonians believed that aches and pains occurring in certain parts of the body were the result of moral misconduct for which deity claimed those body parts. Ritual cleansing, prayers, sacrifices, pilgrimages to shrines were prescribed in combination with magic ceremonies to appease the gods. So-called priest-doctors or wound healers specialised in magic rituals and special therapeutic methods (medication, massage techniques, prescription of certain kinds of food, etc.).

The development of pain treatment was advanced by the Arab-Persian physician Avicena, also known as Ibn Sina (980-1037), who developed causal therapeutic, local analgesic and mind-altering treatment methods for 15 kinds of pain, which he described in his Canon Medicinae (Zimmermann, 2000). Traditional medicine is still used not only in tradition-bound parts of the Middle East, but also in large cities in the Middle East as well as in migration communities in Europe. Various traditional healers are active not only at home but also in countries they migrate to. Such traditional healers include bone healers, religious healers, who work as magicians or sorcerers, Arab physicians carrying on the tradition of the Four Humour Theory, herbalists and women practicing the art of healing, whose help is sought particularly in dealing with gynaecological and obstetrical problems (Heine \& Assion, 2005). For instance, bone healers are still consulted for the treatment of strains, dislocations and suspected or actual bone fractures. As a rule, these religious healers are familiar with the Qur'an, but this is not a prerequisite. In many oriental countries there are also numerous traditional non-Islamic healers, known as hodjas in the Turkish culture. Religious healers are believed by some to be able to recognize magic influences such as the "evil eye", evil spirits or black magic as causes of a disease. Traditional healers are consulted for a wide variety of problems ranging from psychological, neurological, and psychosomatic ailments such as depression, epilepsy or chronic complaints to family problems, financial or work-related difficulties (Heine \& Assion, 2005).

According to Kohnen (2006), every culture has developed strategies for dealing with pain, which correspond to its own values and norms: the Irish, for instance, preferred to withdraw when in pain because they regarded it as bad form to show they were in pain. North Americans preferred to see the doctor as early as possible to describe their complaint without displaying any emotion so that he could immediately initiate a rational treatment. Italians, Greeks, Spaniards and Portuguese expressed pain loudly and clearly in order to enlist sympathy from members of their family. Philippinos accepted their fate fatalistically. Psychological complaints express themselves, i.a., through pain corresponding to the sufferer's cultural background (Borchert et al. 1998). Nigerians, for instance, report having a "sensation of heat" in the head, "worm crawling" and "biting sensations" in the whole body during states of anxiety and depression (Edigbo, 1986). Patients in psychiatric clinics in Chine 
complain of "nervous exhaustion", attended by fatigue, headache, vertigo and gastrointestinal complaints (Kleinman 1980). Many people from South America and the Mediterranean area react to psychological stress with headache, myalgia, sensations of heat, tingling sensation in the feet, heart problems and stomach complaints (Finerman, 1999).

Based on traditional medicine, people from the Middle East associate certain complaints with certain very specific organs shown in Table 1. Associating complaints with specific organs applies to tradition-bound communities in the Middle East and some Balkan countries such as Albania and Macedonia.

Table : Culture-specific syndromes from traditional societies from Middle East and part of the Balkans (Petersen, 1995)

\begin{tabular}{|c|c|c|c|c|}
\hline & Aetiology & Symptoms & Therapy & Associations \\
\hline Fallen navel & $\begin{array}{l}\text { Heavy lifting, } \\
\text { jumping up, hard } \\
\text { work, hard life, stress }\end{array}$ & $\begin{array}{l}\text { Bellyache and } \\
\text { stomach pain, } \\
\text { nausea, vertigo, } \\
\text { weakness, } \\
\text { fatigue }\end{array}$ & $\begin{array}{l}\text { Belly and back } \\
\text { massage, hot } \\
\text { plates, pulling the } \\
\text { navel to correct } \\
\text { position, followed } \\
\text { by rest }\end{array}$ & $\begin{array}{l}\text { Hard life, loss of } \\
\text { moderation }\end{array}$ \\
\hline Burning liver & $\begin{array}{l}\text { Sadness, worry, } \\
\text { deep sorrow }\end{array}$ & $\begin{array}{l}\text { Liver pain, pain in } \\
\text { epigastric region }\end{array}$ & $\begin{array}{l}\text { Reciting passages } \\
\text { from Qur'an, take } \\
\text { herbs and juices }\end{array}$ & $\begin{array}{l}\text { Grief, worry, } \\
\text { longing, loss or } \\
\text { lovesickness }\end{array}$ \\
\hline Back pain & $\begin{array}{l}\text { Family conflicts, } \\
\text { worry, role problem, } \\
\text { hard work }\end{array}$ & $\begin{array}{l}\text { Stabbing and } \\
\text { dragging back } \\
\text { pain, hardly able } \\
\text { to move or to lift } \\
\text { or carry anything }\end{array}$ & $\begin{array}{l}\text { Massages, restrict } \\
\text { movement, rest }\end{array}$ & $\begin{array}{l}\text { Power, seat of } \\
\text { strength and } \\
\text { stamina in men, } \\
\text { weakened "male } \\
\text { identity" (loss of } \\
\text { libido) }\end{array}$ \\
\hline $\begin{array}{l}\text { Calf pain/ "wind } \\
\text { pain" }\end{array}$ & $\begin{array}{l}\text { Grief, worry, } \\
\text { conflicts, longing }\end{array}$ & $\begin{array}{l}\text { Fatigue, } \\
\text { weakness, lack of } \\
\text { drive, the pain is } \\
\text { in a different part } \\
\text { of the body } \\
\text { every day }\end{array}$ & $\begin{array}{l}\text { Massage, rest, } \\
\text { avoid stress }\end{array}$ & $\begin{array}{l}\text { Little } \\
\text { acceptance in } \\
\text { the family or } \\
\text { community, hard } \\
\text { life }\end{array}$ \\
\hline $\begin{array}{l}\text { Feeling of } \\
\text { apprehension }\end{array}$ & $\begin{array}{l}\text { Grief, worry, } \\
\text { feelings of guilt, } \\
\text { longing, anger }\end{array}$ & $\begin{array}{l}\text { Headache, sore } \\
\text { throat, } \\
\text { claustrophobia, } \\
\text { globus symptom, } \\
\text { feeling of } \\
\text { asphyxiation, } \\
\text { shortness of } \\
\text { breath }\end{array}$ & $\begin{array}{l}\text { Hopdja, doctor, } \\
\text { use of wearing } \\
\text { "protective } \\
\text { amulets" }\end{array}$ & $\begin{array}{l}\text { Anxiety, } \\
\text { insecurity }\end{array}$ \\
\hline
\end{tabular}




\section{Somatic disorders}

Since somatoform disorders of these patients play an important role in the work of physicians in private practice and in subsequent treatment in clinics (Keel, 2000), we shall consider these disorders as an example and deal with them in greater detail.

One of the central problems involved in providing medical care to migrants is the somatisation of problems of psychological and social origin in the biomedically oriented sub-system of our society's medical culture Somatoform disorders are a category of disorders that comprises physical symptoms without a sufficient somatic explanation, excessive worry about a physical illness, often associated with depression, anxiety and frequent visits to the physician with negative examination results (Glier \& Erim, 2007; Koch, 2003). In in-patient rehabilitation treatment focused on the treatment of migrants, somatisation disorder is one of the most frequent diagnoses (Koch, 2003; Schmeling-Kludas, 2005; Kizilhan, 2010). The patients from Middle East (Turks, Kurds, Persians, Arabs) concerned describe all complaints as if they were physical and they seem to follow an archaic perception of disease. The subjective complaint can then be symbolically represented by tiredness, crying, use of walking aids, etc.; they present themselves as broken, weak people. As a rule this regressive and appellative bearing is maintained consistently, so that these patients no longer participate even in any domestic activities.

Schmeling-Kludas (2005) examined a group of coeval patients with a migration background, from Turkey, in a psychosomatic clinic ( $n=184), 53 \%$ of them women. Somatoform disorder (62\%) was the most frequent initial diagnosis in 2005 . Koch (2003) and Kizilhan (2008) arrived at similar results with Kurdish, Arab and Persian Patients. From the point of view of gender-specificity, male migrants frequently complain of back problems, whereas among women headaches and pain in the lower abdomen are common. In general, pain in the rheumatic and arthritic and gastrointestinal categories is also a common complaint. In our own experience which gained at the University of Freiburg in Germany in 2008, there is a manifestly higher incidence of gastric disorders among traumatised refugees, especially among those from the Middle East who have experienced torture. It seems that some ethnic groups tend to respond to severe stressors more frequently with gastric disorders rather than with headaches, etc. Fainting spells, paralyses, blockages, hypochondriac symptoms and histrionic behaviour also occur in conjunction with physical complaints (Schmeling-Kludas, 2005; Kizilhan, 2008). 
This strict confinement to physical complaints, whose causes are often difficult to make out, frequently leads to problems in establishing the diagnosis and in therapy (Glier \& Erim, 2007; Kizilhan, 2008).

\section{Diagnostics}

Diagnosing diffuse aches and pains is an interdisciplinary task (comprising various disciplines such as psychology, medicine, psychopharmacology, physiological measures, etc. involved in diagnostics and treatment) for all ethnic groups, top priority being given to searching for a medically treatable cause (Gardea \& Gatchel, 2000). As mentioned previously, many pain syndromes are not accessible to causal treatment, which eliminates or reduces the cause of a disease. An example of causal treatment is the use of an antibiotic to kill off bacteria, thereby eliminating the cause of a disease.

As regards pain, many patients from this cultural group complain of unspecific back pain (which accounted for over $90 \%$ of all cases of persistent back pain) and are unable to explain its exact cause. The same applies to primary headaches such as migraine or headache due to tension or temporomandibular dysfunction (facial neuralgia). Fibromyalgia attended by pain in extensive regions of the body is not accessible to a simple causal explanation (Blumenstiel et al. 2004). For this reason, a psychological diagnosis should always supplement the medical diagnosis in such cases (Lautenbacher, 2004).

The distinguishing culture-specific feature of diagnostics of patients from traditionbound cultures is their lack of knowledge (the Arab-Greek medicine of Four Humour Theory is still regarded as the theoretical basis of the study of diseases) about anatomy and physiology of their body and their traditional notions about pain (magic, curse, punishment, etc.). The pain experience is not confined to a part of the body, but is viewed holistically in relation to the body. And yet an analysis of the circumstances of the first occurrence or of aggravation of the pain, taking into account the individual and collective biography (e.g., ostracism on account of ethnicity and/or religious affiliation in the country of origin, cultural and generational conflicts, etc.) has to be made in order to obtain possible clues regarding the triggering factors. It is important to find out what alleviates or aggravates the pain and what impairments this causes (see Boxl). 
Box 1: Case study of a patient with undefined body pain

Case-Study

Eight years ago, a 28-year-old patient of Turkish background married a Turkish woman who grew up and lived in Germany and emigrated to Germany. Owing to the couple's different social backgrounds (the patient was born and grew up in a Turkish village) and the patient's patriarchal ideas, conflicts keep recurring between them. Following a violent argument, the neighbours called the police. When the patient sees the police in front of his door, he suddenly collapses and is unable to get up. He is taken to the hospital as an emergency case. Several somatic and neurological examinations are performed which yield no abnormal findings. Even after six months, the patient can only move about in his apartment with the aid of walking aids. He complains of undefined whole-body pain and does not believe he can work again. His wife and another relative look after him round the clock. The patient's ability to communicate is limited and he speaks only if he is spoken to. Only following treatment in his native tongue at a psychosomatic clinic does he talk about how the insult and humiliation he felt when the police appeared in front of his door. He had "lost face" because strangers had found out that his wife would not listen to him. Believing he was a "weak man", he had then broken down. Following ten weeks of therapy in which his wife participated, and in the course of which the connection between psychological and physical complaints was explained to him and fresh familial prospects developed (changed gender roles, dealing with tradition-bound family issues in his country of origin, etc) the patient is able to walk again confidently and without walking aids.

In analysing the behaviour of people coming from tradition-oriented cultures, it is especially important to identify relieving and withdrawal behaviour, the patient's response to preceding treatments and the medications the patient is taking. According to the fear-avoidance (FA) model (Vlaeyen \& Linton, 2000) these behaviours may initially be adaptive, but they paradoxically worsen the situation when engaged in later on. Avoidance behaviour may fuel pain, disability and depression (Leeuw et al. 2007). In addition to possible avoidance and anxiety, the general perception of disease in these tradition-bound societies is that when the body is sick it must rest and should not move (Glier \& Erim, 2007).) Families support this relieving behaviour, thereby reinforcing the secondary gain from illness. The family thus becomes an important part of the diagnostic process, which should be taken into account, e.g., in the case of indirect anamnesis. Taking large quantities of drugs, which is associated with drug addiction, is also a familiar behavioural characteristic in tradition-bound societies. The use of opium, mandrake and henbane for pain relief is still practiced in parts of Iran, Afghanistan and Pakistan. Identifying the consequences of the patient's attitude to pain is another precondition for developing a pain model for him. 
The patient's attitudes, evaluations and convictions regarding pain must be ascertained, taking into account their cultural character and generational differences in the sense of a cognition analysis. Resources such as solidarity, familial loyalty, support from the social network and traditional methods of alleviating pain can help the patient adopt a favourable behaviour to cope in a difficult situation. Motivation analysis relates especially to the patient's readiness to change and his or her expectations of self-efficacy. Hence, patients from tradition-bound societies tend to be less willing to accept active attitudes (Glier \& Erim, 2007), such as participating in sports and physiotherapy. At this point the question arises how to motivate these patients to adopt such attitudes. A patient's willingness to "try out" a change in his attitude should already be seen as a positive sign.

The notion, for instance, that pain can be stopped through medication alone can make psychotherapeutic treatment, whose aim, initially, is to learn how "to live with pain", more difficult. In this context, it is very important to take stock of individual and cultural resources (external and/or internal ones) so that they can be applied to bringing about changes in behaviour. This means that apart from focusing on the pain, the significance of the context in which the patient lives should not be underestimated. Legacy stress like arranged marriage, female genital mutilation etc. should be paid as much attention to as culture-specific coping strategies (special relaxation and massage techniques from the country of origin, prayer, involving the family in the treatment process, etc.).

Problem-analytical diagnostics should be supplemented with questionnaires and with keeping a pain diary over a certain period. Implementing this is problematical, especially in the case of patients with a low level of education. Patients from urban areas in Turkey, Iraq or Syria are often illiterate and completely inexperienced in dealing with psychometric tests (Strate \& Koch, 2000; Kirmayer \& Young, 1998), which underlines the need for a very detailed pain and social case history for patients from tradition-bound cultures.

It is also necessary to consider comorbidity, because in literature authors very often proceed from several psychological and physical diagnoses (Glier \& Erim, 2007; Kizilhan, 2008). For instance, a Swiss study conducted in 2009 on pain in migrants by the University of Basel, which was supported by the national research programme of the Health Ministry in Vienna, revealed that apart from pain, migrants from Turkey also suffer from other psychological complaints, the principal ones being depression and anxiety disorders. Many patients either do not recognise the connection between the disorders or they have not been sufficiently informed about it yet (Sleptsova et al. 2009). 


\section{Treatment}

As mentioned in the foregoing, the primary objective of psychological pain therapy is to reduce the patient's impairment, which, as a rule, is associated with a reduction in the patient's subjective pain intensity. Psychological variables like Stress, distress or anxiety as well as mood and emotions, cognitive functioning, and pain behaviour play an important role during the treatment (Linton, 2000). Psychological factors also play a significant role in the aetiology of chronic and acute pain, particularly in the transition to chronic problems. Specific types of psychological variables (perception of illness and pain, personality, culture-specific treatment etc.) emerge and may be important in distinct developmental time frames, also implying that assessment and intervention need to reflect these variables (Linton, 2000).

Most patients from tradition-bound cultures present with a pain model that is reduced to somatic influence factors and in some cases a different understanding of anatomy, i.e., their causal and control attributions are determined in part by simple biomedical assumptions and notions of magic. Consequently, psychoeducation is a necessary component of therapy whose aim is to reinforce convictions of self-efficacy. This should include the use of media such as self-help brochures and videos in the patient's native language. Part of this education is aimed at explaining to the patient how physical and psychological processes overlap. However, this means that the therapist needs to ascertain his patients' level of knowledge in order jointly to develop an explanation model. Patients from tradition-bound cultures are not used to this kind of joint development of an explanation model, their expectation being that the therapist will provide a complete explanation model after the first examination session (Kröner-Herwig, 2005). In earlier times, traditional healers developed the explanation model using a combined approach that involved magic, religious and medical aspects. This is why the patient needs to be informed, already after establishing the diagnosis, about the treatment strategy, which he/she is not familiar with, and its purpose.

The mode of action of relaxation training can be explained through the education content. Relaxation can be seen as a method of self-control to prevent recurrent pain episodes or to reduce a high tonic pain level. Hypnosis induction, dancing and meditation are known in these cultures and can be applied to good effect.

The activity range of many patients is considerably limited, so that their life is reduced to the point where it revolves only around their pain and becomes the centre of their thoughts and behaviour. In patients from tradition-bound cultures, the range of activity is additionally restricted through the assumption that the body must 
rest when in pain. Therefore, trying to expand the range of action, which is necessary to remove patient's behavioural (limited movement), emotional (diminishing depressiveness and feeling of helplessness) and cognitive (restricting pain) limitations, is a challenging task. Building motor activities is of special significance, especially in patients suffering from back pain, so that sport therapy components are an important part of the therapy. It is not only a matter of improving muscle strength and mobility through physiotherapeutic interventions to alleviate pain, but primarily of enabling the patient to alleviate anxiety by "confronting" activities previously regarded as harmful and to help him realise that the feared negative consequences do not materialise (Kröner-Herwig \& Frettlöh, 2004). Thus, diminishing avoidance behaviour has high priority in the treatment.

It is also very important to identify a possible functional role that may be attributed to the pain. It may exist in the form of "rewarding" pain behaviour by getting more attention from the family or through negative reinforcement if the pain enables the patient to avoid aversive situations (being put on sick leave in the case of conflicts at the place of work). The patient also experiences a secondary gain from illness in the form of self-esteem stabilisation (failure attributed to pain as the cause). Pain therapy will not be successful if the significant functional connections cannot be resolved here by mediating adequate problem solutions.

Sustained treatment of the patient by one medical and psychotherapeutic caregiver has proved to be a favourable framework condition, which is relatively difficult owing to these patients' limited knowledge of German. For various reasons, there is still a large deficit in native-speaker caregivers in the outpatient health service (Koch, 2003).

As a rule, an integration of psychological and medical pain treatment can be seen as the optimum therapy. To date, there are no studies on the effectiveness of pain treatment of people from tradition-oriented cultures living in Germany.

The culture-specific aspects summarized in Box 2 which should be taken into consideration in the treatment of patient suffering from diffuse aches and pains who come from tradition-oriented cultures. 
Box 2: Culture-specific aspects to be taken into account in the psychosomatic rehabilitation treatment of Turkish patients

Culture-specific aspects to be taken into account:

Initial examination:

- On the first visit, the patient's report may be limited to, and fixed on, physical aches and pains. Possible psychological conflicts and stresses may initially be rejected. Inadequate fluency in German may make the taking of the case history a challenging task.

- The patient's feeling that the complaints are not taken seriously enough may intensify the fixation on physical complaints.

- Turkish patients with somatization disorders or other pain syndromes report about multiple, recurring, fluctuating, physical symptoms occurring in alternating body organs. These migrating aches and pains can be felt in various parts of the body every day.

- Frequent physical and organic complaints include: headaches, pain in the neck, shoulders, backache, gastric disorders, vertigo, accompanied by fainting spells, shaking, agitation, tiredness, fatigue, lack of drive.

\section{Comorbidity}

- A comorbidity accompanied by other psychological complaints, mainly depression and anxiety disorders, is frequently observed. Many patients do not recognize a possible connection between the disorders or have not been sufficiently informed about it.

Psychoeducation

- Psychoeduactive measures need to be adapted to the patient's cultural origin for the jointly developed model of the disorder to be understood and accepted.

Family involvement

- Involving members of the family in the treatment can be important for both the diagnosis and the treatment in terms of the secondary gain from illness, family dynamics, etc. The family can be involved in supporting the therapy to improve the patient's skills in the sense of social competence and resources.

Medication

- From the patient's point of view, treatment by medication, surgery, physiotherapeutic measures, etc., may initially seem sufficient.

Physiotherapeutic measures and sports involving movement

- Recommending sports activities in which the patient has to move despite the pain he feels often causes irritation, because from his/her viewpoint his/her body is ill and needs rest. Activities do not fit in with the perception many of these patients have of disease; part of the work involved in the treatment must therefore be dedicated to convincing the patient by providing him or her with relevant information, advice and psychotherapy. Despite regular assurances, the question in how far the newly learned movement patterns are integrated into everyday life remains open. However, if there should be no relief from pain, many patients react indignantly, feel offended and not being understood.

- Passive applications such as massages, thermal therapy, etc. are accepted more readily (Glier \& Erim, 2007; Kizilhan, 2010)

Relaxation methods

Relaxation methods such as PMR (Progressive Muscle Relaxation) and other methods of relaxation like hypnosis are accepted, but it is questionable whether these methods are also used in everyday life after the treatment is completed. 
In the psychotherapeutic treatment of patients from tradition-bound cultures with traditional ideas of healing, not only the general treatment strategy should be used, but, as described in the foregoing, the patient's personal disease experience and the possible underlying history of the social network of the country of origin with a different interpretation of conflicts, stresses and diseases should be given greater consideration (Kizilhan, 2010).

\section{Concluding remarks}

The use of culture-sensitive psychotherapy of patients from tradition-bound cultures suffering from diffuse aches and pains is indicated when the patient presents with a high degree of impairment and when he/she makes frequent use of health care services, when the diagnosis can verify that psychological factors have a bearing on the pain experience and impairment and conventional treatment methods do not provide sufficient relief due to these patients' different perception of pain. Empirical evidence with respect to the expanded use of therapy of this group of patients still needs to be provided.

The experience gathered by caregivers to date highlights the importance of interdisciplinary and culture-sensitive therapy, with medical pain therapists and psychotherapists working in cooperation with sports therapists, physiotherapists and other professionals and giving due consideration to the patients' cultural aspects according to the rules of the art.

There are, however, various factors for example in Germany, Austria and Switzerland opposing the realisation of this therapeutic approach, including the health service's structures that are averse to cooperation, the small numbers of native-speaker psychotherapists with advanced pain therapy training and the lack of psychotherapists with an adequate cultural background. In view of the relevance of pain to public health policy and the increasing number of migrants from traditionoriented cultures, steps should be taken to abolish the obstacles on the way to generally accessible, high-quality, interdisciplinary and culture-sensitive psychotherapy.

\section{References}

Arratow, K. (1995). Interkultureller Vergleich der Schmerzwahrnehmung und Krankheitsverarbeitung bei türkischen und deutschen Patienten mit chronischer Polyarthritis. Frankfurt am Main: Lang. 
Bates, M. S., Edwards, T.W., \& Aderson, K.S. (1993). Ethnocultural Influences on Variation in Chronic Pain Perception, Pain, 52, 101-112.

Blumenstiel, K., Bieber, C., \& Eich, W. (2004). Fibromyalgiesyndrom. In H.-D. Basler, C. Franz, B. Kröner-Herwig, H. P. Rehfisch (Eds.), Psychologische Schmerztherapie (pp. 439450). Berlin: Springer.

Branik, E., \& Mulhaxa, A. (2000). Zur Rehabilitation von Patienten aus dem ehemaligen Jugoslawien in der Hochschwarzwald-Klinik St. Blasien. In Heise, T. (Hrg.), Transkulturelle Beratung, Psychotherapie und Psychiatrie in Deutschland (pp. 185-199). Berlin: VWB.

Clark, W., \& Clark, S. (1980). Pain responses in Nepalese porters. Science, 209, 410-412.

Gatchel, R.J, \& Turk, D.C. (1999). Psychosocial factors in pain: critical perspectives. New York: Guilford Press.

Gatchel, R., Peng, Y., Peters, M., Fuchs, P., \& Turk, D. (2007). The biopsychosocial approach to chronic pain: Scientific advances and future direction. Psychological Bulletin, 133, 581-24.

Gardea, M.A., \& Gatchel, R.J. (2000). Interdisciplinary Treatment of Chronic Pain. Current Review of Pain, 4:18-23.

Glier, B., \& Erim, Y. (2007). Schmerz bei Migranten aus der Türkei. In B. Kröner-Herwig, J. Frettlöh, R. Klinger, P. Nilges (Hrsg.), Schmerzpsychotherapie (pp. 231-243). Heidelberg: Springer.

Heine, P., \& Assion, H.J. (2005). Traditionelle Medizin in islamischen Kulturen. In Assion, J. (Hrsg.), Migration und seelische Gesundheit (pp.29-42.). Heidelberg: Springer.

Herzer, H. (2000). Zunehmende Invalidisierung trotz medizinischem Fortschritt bei Schweizern und Ausländern. Schweizerische Ärztezeitung, 81/47, 2668-2672.

Keel, P. (2001). Low Back Pain and Foreign Workers: Does Culture Play an Important Role? In Yilmaz, A. T.; Weiss, M. G.; Riecher-Rössler, A. (Hrg.), Cultural Psychiatry: Euro International Perspectives (pp. 117-125). Basel: Karger.

Kirmayer, L.J., \& Young, A. (1998). Culture and somatization: Clinical, epidemiological and ethnographic perspectives. Psychosomatic Medicine, 60, 420-430. 
Kirmayer, L.J. (2008). Culture and the Metaphoric Mediation of Pain. Transcultural Psychiatry, 45: 318-338.

Kizilhan, J. (2008). Interaktion von Krankheitswahrnehmung und Krankheitsbewältigung bei türkischstämmigen Patienten - Eine vergleichende Studie. Verhaltenstherapie und Verhaltensmedizin, 29 (4), 352-366.

Kizilhan, J. (2010). Kulturelle und transkulturelle Psychotherapie - Verhaltenstherapie interkulturell. In W. Machleidt; A. Heinz (Hrsg.), Praxis der interkulturellen Psychiatrie und Psychotherapie (pp.414-420). München: Elsevier.

Kizilhan, J. (2010). Psychotherapeutisches Arbeiten in institutionellen Settings. In Thomas Hegemann; Ramazan Salman (Hrsg.), Handbuch Transkulturelle Psychiatrie (169-186). Berlin: Psychiatrieverlag.

Kleinman, A. (1980). Patients and Healers in the Context of Culture: An Exploration of the Borderland between Anthropology, Medicine, and Psychiatry. CA: University of California Press.

Koch, E. (2003). Psychiatrie, Psychotherapie, Psychosomatische Rehabilitation und Migration. In Gesunde Integration. Bundesweiter Arbeitskreis Migration und öffentliche Gesundheit (Hrsg.), Koordination: Beauftragte der Bundesregierung für Migration, Flüchtlinge und Integration (pp. 43-53). Berlin: Verlag der Bundesregierung.

Kröner-Herwig, B., \& Frettlöh, J. (2004). Behandlung chronischer Schmerzsyndrome: Plädoyer für einen multiprofessionellen Therapieansatz. In H.-D. Basler, C. Franz, B. KrönerHerwig, H. P. Rehfisch (Eds.), Psychologische Schmerztherapie (pp. 499-524). Berlin: Springer.

Kröner-Herwig, B. (2005). Verhaltenstherapie bei Schmerzen: Wie wirksam ist psychologische Schmerztherapie? Psychotherapie im Dialog, 6, 76-81.

Kröner-Herwig, B. (2009). Chronic pain syndromes and their treatment by psychological interventions. Current Opinion in Psychiatry, 22 (2), 200-204.

Künzler, E. (2005). Ethnopsychoanalytische Untersuchung bei schmerz- und chronisch kranken Arbeitsmigrantinnen und -migranten sowie Flüchtlingen aus dem Kosovo. Dissertation an der Universität Zürich. Zürich: Studentendruckerei. 
Lautenbacher, S. (2004). Schmerzmessung. In H.-D. Basler, C. Franz, B. Kröner-Herwig, H. P. Rehfisch (Eds.), Psychologische Schmerztherapie (pp. 271-288). Berlin: Springer.

Linton, S.J. (2000). A Review of Psychological Risk Factors in Back and Neck Pain. SPINE, $25,9,1148-1156$.

McCracken, L. M., Matthews, A. K., \& Tang, T. S. (2001). A Comparison of Blacks and Whites Seeking Treatment for Chronic Pain,Clinical Journal of Pain, 17 (3), 249-255.

Petersen, A. (1995). Somatisieren die Türken oder psychologisieren wir? Gedanken zur angeblichen Neigung der Türken zum Somatisieren, Curare 18(2):531-540.

Schmeling-Kludas, Ch. (2005). Psychosomatische Rehabilitation von Migranten. In Assion, J. (Hrsg.), Migration und seelische Gesundheit (pp.187-193). Heidelberg: Springer.

Zimmermann, E. (2000). Kulturelle Missverständnisse in der Medizin. Ausländische Patienten besser versorgen. Bern: Huber.

About the author:

Prof. Dr. Jan Ilhan Kizilhan is a psychologist and psychoterapist. His expertise is in psychotraumatology, social medicine (rehabilitation and retirement), forensic and ethnological studies.

Address for correspondence: Jan Ilhan Kizilhan, Institure for Psychology, Department of Rehabilitation Psychology and Psychotherapy, Workgroup Migration and Rehabilitation, University of Freiburg Germany, Engelberger Str. 41, 79106 Freiburg, Germany E-mail address: kizilhan@psychologie.uni-freiburg.de 